\title{
Detection of influenza A(H1N1)V VIRUS by ReAl-time RT-PCR
}

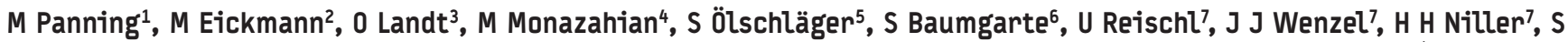 \\ Günther ${ }^{5}$, B Hollmann'1, D Huzly ${ }^{1}$, J F Drexler ${ }^{8}$, A Helmer $^{8}$, S Becker ${ }^{2}$, B Matz ${ }^{8}$, A M Eis-Hübinger ${ }^{8}$, C Drosten (drosten@ \\ virology- bonn.de) ${ }^{8}$ \\ 1. Department of Virology, University of Freiburg, Freiburg, Germany \\ 2. Institute for Virology, University of Marburg, Marburg, Germany \\ 3. TIB Molbiol, Berlin, Germany \\ 4. Governmental Institute of Public Health of Lower-Saxony, Hannover, Germany \\ 5. Bernhard-Nocht-Institute, Hamburg, Germany \\ 6. Institute for Hygiene and the Environment, Hamburg, Germany \\ 7. Institute of Medical Microbiology and Hygiene, University of Regensburg, Regensburg, Germany \\ 8. Institute of Virology, Bonn Medical Centre, Bonn, Germany
}

This article was published on 10 September 2009.

Citation style for this article: Panning M, Eickmann M, Landt O, Monazahian M, Ölschläger S, Baumgarte S, Reischl U, Wenzel JJ, Niller HH, Günther S, Hollmann B, Huzly D, Drexler JF, Helmer A, Becker S, Matz B, Eis-Hübinger AM, Drosten C. Detection of Influenza A(H1N1)v virus by real-time RT-PCR. Euro Surveill. 2009;14(36):pii=19329. Available online: http://www.eurosurveillance.org/ViewArticle.aspx?ArticleId=19329

Influenza A(H1N1)v virus was first identified in April 2009. A novel real-time RT-PCR for influenza $\mathrm{A}(\mathrm{H} 1 \mathrm{~N} 1)$ v virus was set up ad hoc and validated following industry-standard criteria. The lower limit of detection of the assay was 384 copies of viral RNA per $\mathrm{ml}$ of viral transport medium (95\% confidence interval: $273-876$ RNA copies $/ \mathrm{ml}$ ). Specificity was $100 \%$ as assessed on a panel of reference samples including seasonal human influenza $A$ virus H1N1 and H3N2, highly pathogenic avian influenza $A$ virus $\mathrm{H} 5 \mathrm{~N} 1$ and porcine influenza $A$ virus $\mathrm{H} 1 \mathrm{~N} 1, \mathrm{H} 1 \mathrm{~N} 2$ and $\mathrm{H} 3 \mathrm{~N} 2$ samples. The real-time RT-PCR assay for the influenza $A$ matrix gene recommended in 2007 by the World Health Organization was modified to work under the same reaction conditions as the influenza $A(H 1 N 1) v$ virus-specific test. Both assays were equally sensitive. Clinical applicability of both assays was demonstrated by screening of almost 2,000 suspected influenza (H1N1)v specimens, which included samples from the first cases of pandemic H1N1 influenza imported to Germany. Measuring influenza A(H1N1)v virus concentrations in 144 laboratory-confirmed samples yielded a median of $4.6 \log$ RNA copies $/ \mathrm{ml}$. The new methodology proved its principle and might assist public health laboratories in the upcoming influenza pandemic.

\section{Introduction}

Influenza $\mathrm{A}(\mathrm{H} 1 \mathrm{~N} 1) \mathrm{v}$ virus was identified in humans in Mexico and the United States (US) in April 2009 [1] and has since spread worldwide [2]. The World Health Organization (WHO) declared pandemic alert stage 6 on 11 June 2009, indicating an ongoing influenza pandemic [3]. The transmissibility of the influenza $A(H 1 N 1) v$ virus was estimated to be higher than that of seasonal influenza viruses [4]. Influenza A(H1N1)v infections have been primarily seen among young and previously healthy adults suggesting that they are most vulnerable to infection. It remains speculative whether older people might have some level of crossprotection from pre-existing antibodies [4]. Clinical presentation and severity remains unclear, but with the exception of cases in Mexico, most confirmed cases have been characterised by mild influenza-like illness [5]. However, a considerable proportion of patients reported vomiting or diarrhoea which is unusual in seasonal influenza [5]. To limit community or hospital transmission, as well as to initiate antiviral therapy in time as recommended by the $\mathrm{WHO}$, the rapid detection of the virus in suspected cases remains crucial [6].

After the emergence of the H1N1 influenza pandemic no specific or well-validated diagnostic test was available. Rapid antigen-based tests for seasonal influenza seem to be compatible with pandemic H1N1 influenza, even though anecdotal reports exist on falsenegative test results [1]. In the clinical diagnosis of influenza, nucleic acid testing by RT-PCR has widely replaced traditional virus culture due to shorter turnaround times and increased sensitivity [7]. Broadly reactive RT-PCR assays are indeed capable of detecting influenza $A(H 1 N 1) v$ virus [1], but they may lack sensitivity and cannot differentiate between contemporary influenza $A$ viruses and influenza $\mathrm{A}(\mathrm{H} 1 \mathrm{~N} 1) \mathrm{v}$ virus [8].

Immediately after the recognition of the new virus, sequence information was made publicly available by the Global Initiative on Sharing Avian Influenza Data (GISAID) [9]. We used this information to design and distribute a real-time RT-PCR assay specific for influenza $A(H 1 N 1) v[10,11]$. In parallel, a published screening assay was evaluated for its ability to detect both influenza $A(H 1 N 1) v$ and seasonal influenza A virus [12]. This second assay served as a confirmatory test for pandemic H1N1 influenza, as well as for discriminating seasonal influenza from influenza $A(H 1 N 1) v$ infection. Pre-validated and quality-confirmed sets of oligonucleotides for both assays were centrally distributed within a large network of laboratories within Germany, covering most university hospitals and many public health institutions $[13,14]$.

On 27 April 2009, samples from the first imported case of pandemic H1N1 influenza in Germany were received before specific assays for pandemic H1N1 influenza became available. The diagnosis was therefore confirmed overnight by sequencing of initial amplification products from an assay not specific for 
pandemic H1N1 influenza [8]. The second imported case in Germany occurred on the evening of 28 April, the day the assay was first distributed. This case was diagnosed primarily with the new assays within three hours of receipt of the specimen. Here we report technical and clinical performance of the novel set of diagnostic tests on a large panel of samples.

\section{Methods}

Patient samples from the H1N1 influenza pandemic

At the beginning of the pandemic, 106 samples from 106 individual patients with acute onset of respiratory symptoms accompanied by fever and a recent travel history to countries with sustained human-to-human transmission of pandemic H1N1 influenza were analysed with the novel pandemic H1N1 influenza real-time PCR assay as well as the general influenza A (matrix gene) screening assay. These samples were collected and analysed in Bonn, Freiburg, Hamburg, Marburg and Regensburg. One of these samples was from an imported laboratory-confirmed case of influenza $A(H 1 N 1) v$ infection (Patient 1), and one from the first patient with hospital-aquired influenza $A(\mathrm{H} 1 \mathrm{~N} 1) v$ infection in Germany (Patient 2). Patient 1 was diagnosed in Hamburg. Patient 2 was from Regensburg and had been infected by the first imported case to Germany [8].

A further 1,838 suspected cases were analysed at Bonn University Medical Centre later in the pandemic, until 30 July 2009. Of those, 211 cases were laboratory-confirmed pandemic H1N1 influenza. A selection of 144 pandemic H1N1 influenzapositive samples were used to determine virus concentrations in respiratory samples.

Specimens included nasopharyngeal swabs in viral transport medium, sputum, broncho-alveolar lavage fluid, throat washes, as well as cell culture medium containing reference virus strains. Viral nucleic acid was extracted using the Viral RNA mini kit (Qiagen).

\section{Pandemic H1N1 influenza-specific real-time RT-PCR assays}

Real-time RT-PCR oligonucleotides for influenza A(H1N1) $v$ virus targeting the haemagglutinin (HA) gene were designed with Primer Express version 2 (Applied Biosystems) software. GenBank Accession number FJ966082 served as the template sequence. Several primer-and-probe combinations were evaluated experimentally to determine the most efficient combination.

A PCR reaction (One-step RT-PCR kit, Qiagen) of $25 \mu \mathrm{l}$ for the pandemic $\mathrm{H} 1 \mathrm{~N} 1$ influenza specific assay contained: 5 $\mu \mathrm{l}$ of RNA extract, $1 \mathrm{x}$ reaction buffer, $400 \mu \mathrm{M}$ of each dNTP, $40 \mathrm{ng} / \mu \mathrm{l}$ bovine serum albumine, $400 \mathrm{nM}$ of primer H1SWS (CATTTGAAAGGTTTGAGATATTCCC; GenBank Accession Number FJ966082, nt 380-404), 400 nM of primer H1SWAs (ATGCTGCCGTTACACCTTTGT; nt 457-437), 200 nM of probe H1SWP (FAM-ACAAGTTCATGGCCCAATCATGACTCG-BBQ; nt 409-435) and $1 \mu \mathrm{l}$ of Enzyme Mix. All primers and probe were synthesised by TIB Molbiol, Berlin, Germany. Thermal cycling was done on a LightCycler 2.0 (Roche Diagnostics) instrument under the following conditions: $30 \mathrm{~min}$ at $50{ }^{\circ} \mathrm{C} ; 15 \mathrm{~min}$ at $95{ }^{\circ} \mathrm{C} ; 45$ cycles of $15 \mathrm{~s}$ at $94{ }^{\circ} \mathrm{C}$; and $30 \mathrm{~s}$ at $60^{\circ} \mathrm{C}$.

The same protocol can be run on a Lightcycler 480 system (Roche Diagnostics) without loss of sensitivity (data not shown). No other commercial test kits were evaluated in this study.

\section{General influenza A (MA) real-time RT-PCR}

Published real-time PCR primers targeting the matrix (MA) gene of influenza A virus were used [12]. A PCR reaction (One-step RT-PCR kit, Qiagen) of $25 \mu \mathrm{l}$ for the matrix assay contained $5 \mu \mathrm{l}$ of RNA extract, $1 \mathrm{x}$ reaction buffer, $400 \mu \mathrm{M}$ of each dNTP, $40 \mathrm{ng} / \mu \mathrm{l}$ bovine serum albumine, $400 \mathrm{nM}$ of primer M InfA F (AAGACCAATCCTGTCACCTCTGA; GenBank Accession number CY038773; nt 175-197), 400 nM of primer M_InfA R (CAAAGCGTCTACGCTGCAGTCC; nt 269-248), $200 \mathrm{nM}$ of probe M_InfA TM (FAM-TTTGTGTTCACGCTCACCGT-BBQ; nt 215-234) and $1 \mu \mathrm{l}$ of Enzyme Mix. Thermal cycling was done on a LightCycler 2.0 (Roche Diagnostics) instrument under the following conditions: $30 \mathrm{~min}$ at $50{ }^{\circ} \mathrm{C} ; 15 \mathrm{~min}$ at $95^{\circ} \mathrm{C} ; 45$ cycles of $15 \mathrm{~s}$ at $94^{\circ} \mathrm{C}$; and $30 \mathrm{~s}$ at $60^{\circ} \mathrm{C}$.

As above, the same protocol can be run on a Lightcycler 480 system (Roche Diagnostics) without loss of sensitivity (data not shown).

\section{Construction of in vitro-transcribed RNA controls}

A partial HA gene fragment from the virus isolated from Patient 1 was amplified using primers HA_InfA CaF1 (CAACAGACACTGTAGACACAG; GenBank Accession number FJ966082; nt 86-106) and HA_InfA_CaR1 (TTCCATTGCGAATGCATATCTCGG; nt 825-802) and cloned into a pJET12 plasmid vector (Fermentas). The complete MA gene from the same virus was amplified using primers Matrix_Cal_F (TAACCGAGGTCGAAACGTACG; GenBank FJ969513; nt 11-31) and Matrix_Cal_R (TTACTCTAGCTCTATGTTGAC; nt 982-902) and ligated and cloned as described above. Plasmids were transcribed into RNA by means of a MEGAScript T7 in vitro transcription kit (Ambion) as described [15]. RNA in vitro transcripts were purified and quantified spectrophotometrically. Sequence integrity was checked by sequencing on an $\mathrm{ABI} 3100$ automated sequencer (Applied Biosystems).

\section{Determination of lower limit of detection}

Initial experiments were done with RNA extracted from nasopharyngeal specimens of Patient 1 . To exactly determine the lower limit of detection (LOD) of both real-time RT-PCR assays, different concentrations of HA RNA transcript as well as MA RNA transcript were spiked into viral transport medium, and RNA was extracted using the viral RNA mini kit (Qiagen). Influenza-negative swabs to account for patient derived matrix effects were not used since possible PCR inhibitors will most likely be efficiently diluted by the viral transport medium. Five replicates of each concentration were processed and analysed by the pandemic H1N1 influenza (HA RNA transcript) and the screening (MA RNA transcript) realtime RT-PCR, respectively. Fractions of positive results for each concentration were subjected to probit regression analysis using the Statgraphics software package (Manugistics).

\section{Quantitive results for pandemic H1N1 influenza}

Nasal and throat swabs from a selection of 144 cases of pandemic H1N1 influenza (see above) were used to determine influenza $A(H 1 N 1)$ v virus RNA concentrations in the H1N1 influenza-specific (HA) real-time assay using in vitro-transcribed RNA as described [15]. An external curve was generated and cycle threshold values were transformed into log RNA copies/ml.

Results

Pandemic H1N1 influenza-specific (HA) real-time RT-PCR assays

Tenfold serial dilution series of in vitro-transcribed HA RNA were tested in duplicates in the pandemic H1N1 influenza (HA) 
RT-PCR (Figure 1A) and the general influenza A (MA) screening RT-PCR (Figure 1B), in order to determine the linear range of both real-time RT-PCR assays. The resulting end-points of detection in the pandemic H1N1 influenza (HA) RT-PCR were 1 and 5 RNA copies/ $\mu$ in different experiments. A linear correlation between the

\section{F I G U R E 1}

Linear range of pandemic H1N1 influenza (HA) real-time RT-PCR and general influenza A (MA) screening real-time RT-PCR

A

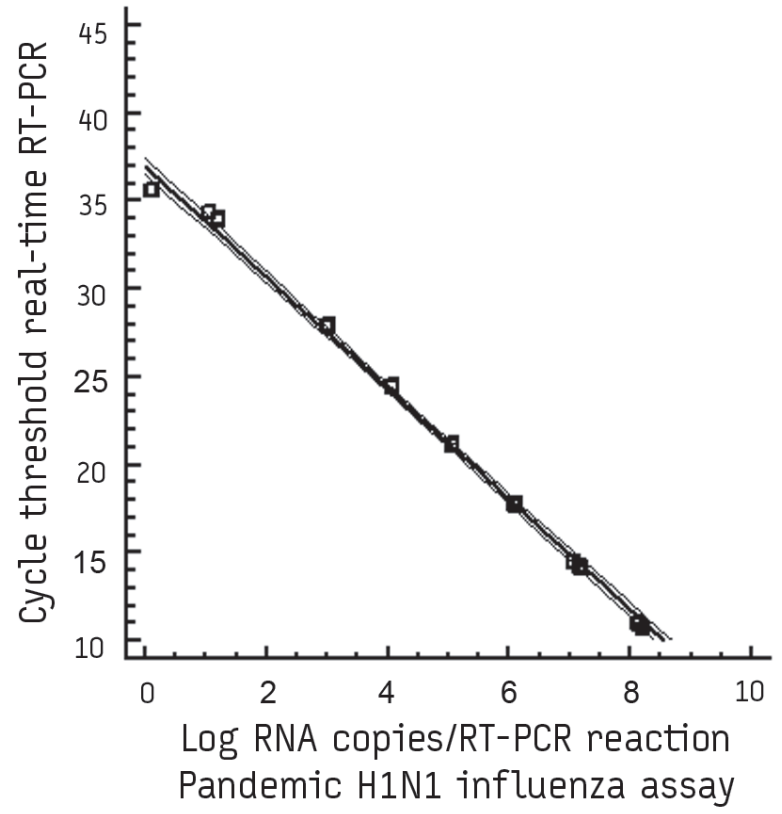

B

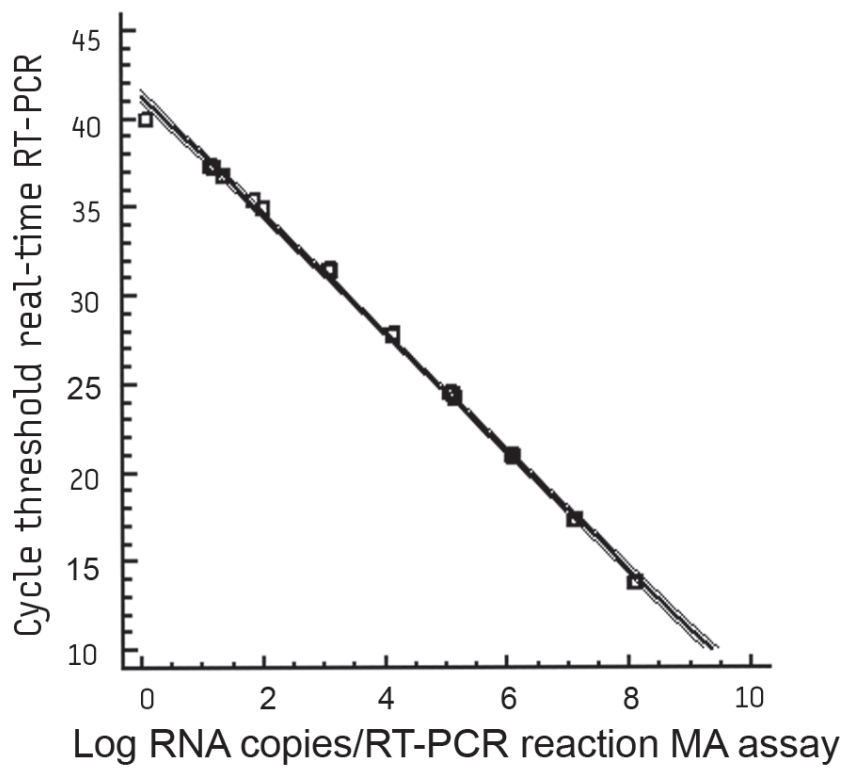

HA: haemagglutinin gene; MA: matrix gene.

Observed cycle thresholds are plotted against log RNA concentration (square points). Thick centre lines represent the prediction line, thin lines the $95 \%$ confidence intervals.

\section{F I G U R E 2}

Probit analysis of pandemic H1N1 influenza (HA) real-time RT-PCR and general influenza A (MA) screening real-time RT-PCR

A

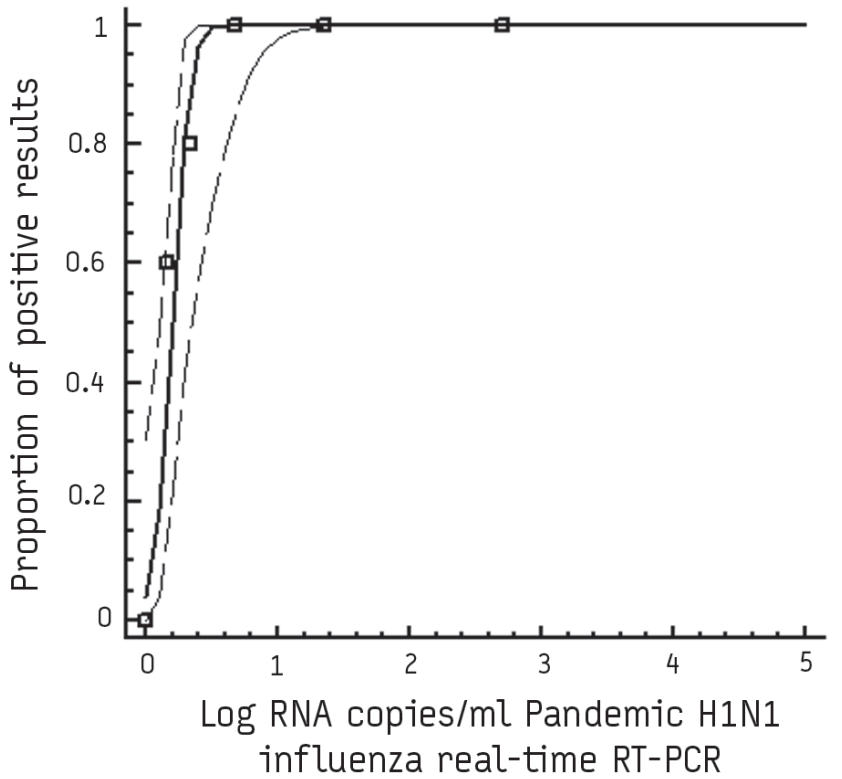

B

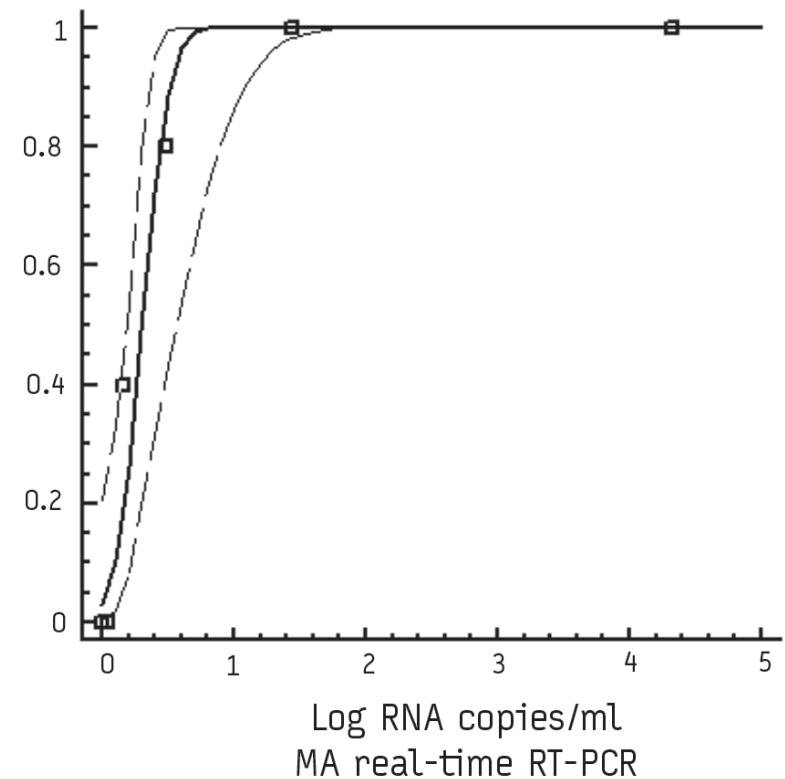

HA: haemagglutinin gene; MA: matrix gene.

Depicted are the observed proportion of positive test results in parallel experiments (square data points), as well as the derived predicted proportion of positive results (line) at a given input concentration of RNA. The centre line denotes the prediction, thin broken border lines are $95 \%$ confidence intervals. 
log starting copy number and threshold cycle was achieved from

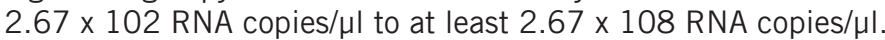

\section{TA B L E 1}

Serial tenfold dilutions of RNA extracted from Patient 1 tested by the MA broad-range assay as well as the pandemic H1N1 influenza-specific real-time RT-PCR

\begin{tabular}{|l|c|c|c|c|c|c|}
\hline & \multicolumn{6}{|c|}{$\log _{10}$ dilution series RNA, Patient 1} \\
\hline & $10^{-2}$ & $10^{-3}$ & $10^{-4}$ & $10^{-5}$ & $10^{-6}$ & $10^{-7}$ \\
\hline MA assay & + & + & + & + & - & - \\
\hline Pandemic H1N1 influenza assay & + & + & + & + & - & - \\
\hline
\end{tabular}

MA: matrix protein gene.

+ indicates a positive result, - denotes a negative result.
The slope was calculated as 3.15 for the pandemic H1N1 influenza (HA) assay. Based on the slope value, PCR efficiency was calculated to be 1.0 (according to the PCR amplification formula $E=10^{(1 / \text { slope })}-1 ; E$ being the PCR efficiency), indicating $100 \%$ efficient PCR amplification.

The 95\% LOD was determined next. This common technical specification indicates the concentration down to which an assay will detect the analyte with at least $95 \%$ probability. To generate defined reference material that mimics clinical samples, different concentrations of in vitro-transcribed RNA were spiked into viral transport medium in which swabs are routinely received in the laboratory. Each analyte concentration was tested in five replicate reactions in each RT-PCRassay and yielded a 95\% LOD of 384 RNA copies/ml (95\% Cl: 273-876 RNA copies/ml) for the pandemic H1N1 influenza (HA) assay (Figure 2A).

\section{TA B L E 2}

Specificity testing of influenza specimens of porcine and human origin by MA broad-range assay and pandemic H1N 1 influenza-specific assay

\begin{tabular}{|l|l|c|c|}
\hline \multicolumn{2}{|l|}{} & \multicolumn{2}{c|}{ Real-time RT-PCR result } \\
\hline \multicolumn{2}{|l|}{ Influenza virus specimen } & MA assay & Pandemic H1N1 influenza assay \\
\hline 1 & A/Swine/Hannover/1/81(H1N1) & + & - \\
\hline 2 & A/Swine/Germany/2/81 (H1N1) & + & - \\
\hline 3 & A/Swine/Italy/21599-3/03 (H1N1) & + & - \\
\hline 4 & A/Swine/Borkum/1832/00 (H1N2) & + & - \\
\hline 5 & A/Swine/Italy/30019-2/07 (H1N2) & + & - \\
\hline 6 & A/Swine/Italy/65260-11/06 (H3N2) & + & - \\
\hline 7 & A/Bayern/7/95 (H1N1) & + & - \\
\hline 8 & A/Beijing/262/95 (H1N1) & + & - \\
\hline 9 & A/Brazil/11/78 (H1N1) & + & - \\
\hline 10 & A/Moscow/10/99 (H3N2) & + & - \\
\hline 11 & Influenza A clinical samples 2008-9 (n=120) & \\
\hline & Influenza quality assessment samples & & - \\
\hline 12 & A/Fukushima/141/06 (H1N1) & + & - \\
\hline 13 & A/New Caledonia/20/99 (H1N1) & + & - \\
\hline 14 & A/Brisbane/10/07 (H3N2) & + & - \\
\hline 15 & A/Brisbane/59/07 (H3N2) & + & - \\
\hline 16 & A/California/7/04 (H3N2) & + & - \\
\hline 17 & A/Wisconsin/67/06 (H3N2) & + & - \\
\hline 18 & A/duck/Vietnam/TG24-01/05 (H5N1) & + & - \\
\hline 19 & A/whooper swan/Germany/R65-2/06 (H5N1) & + & - \\
\hline 20 & B/Florida/4/06* & - & - \\
\hline 21 & B/Malaysia/2506/04** & + & - \\
\hline 22 & B/Shanghai/361/02** & + & - \\
\hline & & + & \\
\hline
\end{tabular}

MA: matrix protein gene.

+ depicts a positive, - a negative result.

*All 120 samples tested positive in the MA and negative in the pandemic H1N1 influenza assay.

${ }^{* *} A l l$ influenza B samples tested positive in an influenza B- specific RT-PCR (data not shown). 


\section{General influenza A (MA) real-time RT-PCR}

For confirmation of influenza A virus detection, oligonucleotides from several published and evaluated RT-PCR assays were checked against the genome sequence of influenza $A(H 1 N 1) v$ virus. One assay developed by Ward et al. [12], was targeted against the MA gene. This assay had been recommended by the WHO for general influenza $A$ virus screening, including avian influenza $A$ virus (H5N1), matched the influenza $A(H 1 N 1) v$ virus sequence except for one base pair mismatch (C-T) 13 nucleotides from the 3 '-end of the plus strand primer [16]. This mismatch was considered uncritical. The assay was optimised in order to comply with the same cycling conditions as the pandemic H1N1 influenza (HA) assay, so that both assays could be run in parallel in one LightCycler instrument. Serial dilution series of patient RNA were tested with both assays. As shown in Table 1, both assays were equally sensitive.

Using in vitro-transcribed MA RNA, the MA assay yielded an endpoint dilution sensitivity of 13 RNA copies per $\mu$ l. The linear range extended from $1.28 \times 102$ RNA copies/ $\mu$ to at least 1.28x108 RNA copies/ $\mu$ l. The slope was calculated as 3.35, and PCR efficiency was 0.99 (Figure 1). In a probit analysis as described above, the MA-based broad range assay showed a 95\% LOD of 570 RNA copies/ml (95\% Cl: 397-1,232 RNA copies/ml) (Figure 2).

\section{Specificity of the pandemic H1N1 influenza (HA) assay}

Specificity of the H1-based pandemic H1N1 influenza assay was confirmed on a panel of 21 stored clinical samples containing adenovirus $(n=1)$, respiratory syncytial virus (RSV)-A ( $n=5), R S V-B$ $(n=2)$, human coronavirus OC43 $(n=1)$, human coronavirus $229 \mathrm{E}$ $(n=3)$, human coronavirus NL63 $(n=1)$, human metapneumovirus $(n=1)$, parainfluenzavirus $3(n=1)$ and entero-/rhinovirus $(n=6)$ as assessed by xTAG Respiratory Viral Panel (Luminex; authors' unpublished data). As expected, none of these pathogens reacted with the pandemic H1N1 influenza real-time RT-PCR indicating its high specificity. The MA-based broad range assay was not evaluated on this panel but demonstrated its specificity as described. [12].

Because of the porcine origin of pandemic H1N1 influenza [17], the assay was also tested on cell culture supernatants containing porcine influenza A virus reference samples (Table 2, rows 1-6).

To exclude cross-reactivity with human influenza viruses, we tested cell culture supernatants of human influenza virus strains (Table 2, rows 7-10) as well as 120 original clinical samples from patients with seasonal influenza A virus infection from the 2008-9 season, including $\mathrm{H} 1 \mathrm{~N} 1$ and $\mathrm{H} 3 \mathrm{~N} 2$ viruses (Table 2, row 11). All of these were negative in the pandemic $\mathrm{H} 1 \mathrm{~N} 1$ influenza $(\mathrm{HA})$ assay and positive in the MA-based broad-range assay (shown in Table 2).

In addition, 30 stored samples from recent quality assessment tests for influenza virus detection were evaluated (Table 2, rows 12-22). None of these materials, which included various dilutions of contemporary human influenza $A(H 1 N 1, H 3 N 2)$ as well as avian influenza $\mathrm{A}(\mathrm{H} 5 \mathrm{~N} 1)$ and influenza $B$ virus samples yielded a positive result with the pandemic $\mathrm{H} 1 \mathrm{~N} 1$ influenza $(\mathrm{HA})$ assay. All influenza A samples were positive in the general influenza A MA-based assay.

\section{Clinical evaluation}

A preliminary clinical evaluation was done in five public health and university laboratories in Germany. By mid-May 2009 samples from 106 individual patients suspected on clinical and epidemiological grounds to have aquired influenza $A(H 1 N 1) v$ infection had been analysed with the new assays. Of these 106 samples, 102 gave negative results in both assays. Three of the four remaining samples tested positive in the MA-based assay, but were negative in the HA-based pandemic H1N1 influenza assay. After to further confirmatory testing, these three samples turned out to be human seasonal influenza A virus infections (data not shown).

The last sample was positive in both assays. This patient (Patient 1 ) was preliminary classified as having acute influenza $A(H 1 N 1)$ $v$ infection. She had a recent travel history to Mexico and sought medical treatment for fever and acute respiratory symptoms in Hamburg on 28 April 2009. Influenza A(H1N1)v infection was confirmed by the National Influenza Reference Centre at the Robert-Koch Institute (RKI), Berlin.

Material from another confirmed case (Patient 2) was provided retrospectively for testing with both assays. This patient had not reported a recent travel history but shared a hospital room with the first imported case of pandemic H1N1 influenza in Germany [8]. The patient had only very mild symptoms. Both assays reacted clearly positive.

Later in the pandemic, further samples of suspected influenza $A(H 1 N 1) v$ infection were analysed with the new assay at Bonn University Medical Center, so far 1,838 samples. Among those, 221 confirmed cases of pandemic H1N1 influenza have been identified as of 30 July.

\section{Quantitative results for pandemic H1N1 influenza}

Viral RNA concentrations were measured in samples from 144 laboratory-confirmed cases of pandemic H1N1 influenza for whom RNA preparations were available at Bonn University Medical Center. A median of 4.6 influenza $\mathrm{A}(\mathrm{H} 1 \mathrm{~N} 1) \mathrm{v}$ virus log RNA copies per ml of viral transport medium was determined in the pandemic $\mathrm{H} 1 \mathrm{~N} 1$ influenza-specific (HA) assay (range 2.1-7.9 log RNA copies/ml), indicating rather low virus concentrations.

Discussion

A real-time RT-PCR specific for influenza $A(H 1 N 1) v$ virus was set up immediately after first sequence information became available, and evaluated thoroughly from a technical and clinical point of view.

In the currently evolving influenza pandemic, rapid and reliable case identification remains crucial to limit extensive transmission and to initiate therapy [18]. The performance of antigen-based tests for pandemic $\mathrm{H} 1 \mathrm{~N} 1$ influenza has not been extensively evaluated so far, but anecdotal reports do exist of false negative test results in confirmed cases of pandemic H1N1 influenza [19]. A further issue with antigen-based tests is the fact that they do not discriminate between seasonal influenza A virus strains and influenza $A(H 1 N 1)$ $v$ virus strains. The concurrence of the first wave of the pandemic H1N1 influenza and regular seasonal influenza in the southern hemisphere poses a risk of intra-human reassortation, making it highly relevant to discriminate between viruses by laboratory testing [20].

Real-time RT-PCR has proven highly effective in the detection of seasonal human influenza [21]. First reports on clinical cases in which influenza $A(\mathrm{H} 1 \mathrm{~N} 1)$ v virus was detected by real-time RT-PCR have become available, but the assays used so far had not been validated thoroughly from a technical point of view [19,22,23]. Our study presents the first fully validated real-time RT-PCR for pandemic H1N1 influenza. Its LOD at 384 RNA copies/ml (95\% LOD, probit analysis) is comparable to that of commercial test kits $[21,24]$. Specificity was proven on a comprehensive panel of 
120 clinical samples containing contemporary human influenza $A$ and $B$ viruses, on reference specimens from an external quality assurance study, and on a panel of selected swine influenza viruses. Clinical applicability was demonstrated on the first imported cases of pandemic H1N1 influenza in Germany, and by testing more than 200 confirmed cases later in the pandemic without any false positive or negative results. Interestingly rather low virus concentrations were measured by the pandemic H1N1 influenzaspecific real-time RT-PCR, compared to viral loads seen in seasonal influenza $[25,26]$. It remains unclear if this is related to the host or propensity of the virus itself.

We have also shown in this study that a broad-range influenza A assay recommended by WHO and based on the MA gene had the same high sensitivity as the HA-based pandemic H1N1 influenza-specific assay and can be used for simultaneous detection of influenza $A(H 1 N 1) v$ virus and seasonal strains [12]. It can thus serve as a confirmatory test and for discriminating influenza $A(H 1 N 1) v$ virus from seasonal strains. Both assays were developed to allow for parallel testing on a single real-time PCR instrument, reducing the time of turnover significantly [27]. Use of the combined assays facilitates decentralised testing in clinical laboratories, which is necessary when the demands for testing will exceed the capacities of reference laboratories during the upcoming pandemic $[20,28]$. In this respect, it is important to mention that the validation data presented in this report have been generated by five different laboratories that had obtained the assays in form of protocols and pre-evaluated oligonucleotides. Recent experiences during the epidemics of severe acute respiratory syndrome (SARS) and chikungunya disease have demonstrated that rapid provision of pre-formulated diagnostic assays can facilitate immediate diagnostic capacity building [13,14,29].

To conclude, we could demonstrate that the testing alogrithm proposed here is a feasible approach and might assist public health laboratories in the upcoming influenza season.

\section{Acknowledgements}

We are grateful to Björn Eberle and Ulrike Reber for excellent technical assistance.

We would like to thank Dr. Emanuela Foni (IZSLER, Parma, Italy) for providing the viruses A/Swine/Italy/21599-3/03 (H1N1), A/Swine/ Italy/30019-2/07 (H1N2) and A/Swine/Italy/65260-11/06 (H3N2). Swine influenza viruses were also kindly provided by Dr. Mikhail Matrosovich (Institute for Virology, Marburg, Germany).

This work was supported by the European Union projects RiViGene, EVA, and EMPERIE.

\section{References}

1. Centers for Disease Control and Prevention (CDC). Update: swine influenza $A$ (H1N1) infections--California and Texas, April 2009. MMWR Morb Mortal Wkly Rep. 2009 1;58(16):435-7.

2. World Health Organization. Pandemic (H1N1) 2009 - update 64.04 September 2009. Available from: http://www.who.int/csr/don/2009_09_04/en/index.html

3. World Health Organization. World now at the start of 2009 influenza pandemic. 11 June 2009. Available from: http://www.who.int/mediacentre/ news/statements/2009/h1n1_pandemic_phase6_20090611/en/

4. Fraser C, Donnelly CA, Cauchemez S, Hanage WP, Van Kerkhove MD, Hollingsworth TD, et al. Pandemic potential of a strain of influenza A (H1N1): early findings. Science. 2009;324(5934):1557-61.

5 Dawood FS, Jain S, Finelli L, Shaw MW, Lindstrom S, Garten RJ, et al. Emergence of a novel swine-origin influenza A (H1N1) virus in humans. N Engl J Med. 2009;360(25):2605-15.

6. World Health Organization. WHO Guidelines for Pharmacological Management of Pandemic (H1N1) 2009 Influenza and other Influenza Viruses. Geneva:WHO; 2009. Available from: http://www.who.int/csr/resources/publications/swineflu/ h1n1_guidelines_pharmaceutical_mngt.pdf
7. Petric M, Comanor L, Petti CA. Role of the laboratory in diagnosis of influenza during seasonal epidemics and potential pandemics. J Infect Dis. 2006;194 Suppl 2:S98-110.

8. Melzl H, Wenzel JJ, Kochanowski B, Feierabend K, Kreuzpaintner B, Kreuzpaintner $E$, et al. First sequence-confirmed case of infection with the new influenza A(H1N1) strain in Germany. Euro Surveill. 2009;14(18). pii: 19203. Available from: http://www.eurosurveillance.org/ViewArticle. aspx?ArticleId $=19203$

9. World Health Organization. Viral gene sequences to assist update diagnostics for influenza A (H1N1). Geneva:WHO; 2009. Available from: http://www.who.int/ csr/disease/swineflu/swineflu_sequences_labs_20090425.pdf

10. Drosten C, Gunther S, Preiser W, van der Werf S, Brodt HR, Becker S, et al. Identification of a novel coronavirus in patients with severe acute respiratory syndrome. N Engl J Med. 2003;348(20):1967-76.

11. Abbott A. German virologist's race for swine flu test. 2009 April 30. Nature. doi:10.1038/news.2009.424. Available from: http://www.nature.com/ news/2009/090429/full/news.2009.424.html

12. Ward CL, Dempsey MH, Ring CJ, Kempson RE, Zhang L, Gor D, et al. Design and performance testing of quantitative real time PCR assays for influenza $A$ and B viral load measurement. J Clin Virol. 2004;29(3):179-88.

13. Abbott A. SARS testing: First past the post. Nature. 2003;423(6936):114.

14. Panning M, Charrel RN, Mantke OD, Landt O, Niedrig M, Drosten C. Coordinated implementation of chikungunya virus reverse transcription-PCR. Emerg Infect Dis. 2009;15(3):469-71.

15. Drosten C, Panning M, Drexler JF, Hansel F, Pedroso C, Yeats J, et al. Ultrasensitive monitoring of HIV-1 viral load by a low-cost real-time reverse transcription-PCR assay with internal control for the 5 ' long terminal repeat domain. Clin Chem. 2006;52(7):1258-66.

16. World Health Organization. Recommendations and laboratory procedures for detection of avian influenza $\mathrm{A}(\mathrm{H} 5 \mathrm{~N} 1)$ virus in specimens from suspected human cases. Geneva:WHO; 2007. Available from: http://www.who.int/csr/ disease/avian_influenza/guidelines/RecAIlabtestsAug07.pdf

17. Smith GJ, Vijaykrishna D, Bahl J, Lycett SJ, Worobey M, Pybus OG, et al. Origins and evolutionary genomics of the 2009 swine-origin H1N1 influenza A epidemic. Nature. 2009 Jun 25;459(7250):1122-5.

18. Centers for Disease Control and Prevention (CDC). Update: novel influenza $A$ (H1N1) virus infection - Mexico, March-May, 2009. MMWR Morb Mortal Wkly Rep. 2009;58(21):585-9.

19. Lau SK, Chan KH, Yip CC, Ng TK, Tsang OT, Woo PC, et al Confirmation of the first Hong Kong case of human infection by novel swine-origin influenza $A$ (H1N1) virus using ultra-rapid, real-time reverse transcriptase PCR. J Clin Microbiol. 2009;47(7):2344-6.

20. World Health Organization. Influenza A(H1N1) - update 43. 3 June 2009. Available from: http://www.who.int/csr/don/2009_06_03/en/index.html

21. van Elden LJ, Nijhuis M, Schipper P, Schuurman R, van Loon AM. Simultaneous detection of influenza viruses $A$ and $B$ using real-time quantitative PCR. J Clin Microbiol. 2001;39(1):196-200.

22. Poon LL, Chan KH, Smith GJ, Leung CS, Guan Y, Yuen KY, et al. Molecular detection of a novel human influenza (H1N1) of pandemic potential by conventional and real-time quantitative RT-PCR assays. Clin Chem. 2009;55(8):1555-8.

23. Ellis J, Iturriza M, Allen R, Bermingham A, Brown K, Gray J, et al. Evaluation of four real-time PCR assays for detection of influenza $A(H 1 N 1) v$ viruses. Euro Surveill. 2009;14(22):pii=19230. Available from: http://www.eurosurveillance. org/ViewArticle.aspx?ArticleId=19230

24. Gharabaghi F, Tellier R, Cheung R, Collins C, Broukhanski G, Drews SJ, et al. Comparison of a commercial qualitative real-time RT-PCR kit with direc immunofluorescence assay (DFA) and cell culture for detection of influenza $A$ and $B$ in children. J Clin Virol. 2008;42(2):190-3.

25. Lee N, Chan PK, Hui DS, Rainer TH, Wong E, Choi KW, et al. Viral loads and duration of viral shedding in adult patients hospitalized with influenza. $J$ Infect Dis. 2009;200(4):492-500.

26. de Jong MD, Simmons CP, Thanh TT, Hien VM, Smith GJ, Chau TN, et al. Fatal outcome of human influenza A (H5N1) is associated with high viral load and hypercytokinemia. Nat Med. 2006;12(10):1203-7.

27. Drosten C, Gottig S, Schilling S, Asper M, Panning M, Schmitz H, et al. Rapid detection and quantification of RNA of Ebola and Marburg viruses, Lassa virus, Crimean-Congo hemorrhagic fever virus, Rift Valley fever virus, dengue virus, and yellow fever virus by real-time reverse transcription-PCR. J Clin Microbiol. 2002;40(7):2323-30.

28. Cockerill FR 3rd, Smith TF. Response of the clinical microbiology laboratory to emerging (new) and reemerging infectious diseases. J Clin Microbiol. 2004;42(6):2359-65.

29. Drosten C, Doerr HW, Lim W, Stöhr K, Niedrig M. SARS molecular detection external quality assurance. Emerg Infect Dis. 2004;10(12):2200-3. 